C2019, Elsevier. Licensed under the Creative Commons Attribution-NonCommercialNoDerivatives 4.0 International http://creativecommons.org/about/downloads 


\title{
Impact response of Kevlar/rubber composite
}

\author{
Amin Khodadadi ${ }^{1}$, Gholamhossein Liaghat ${ }^{1,2 *}$, Hamed Ahmadi ${ }^{1}$, Ahmad Reza Bahramian $^{3}$, \\ Omid Razmkhah ${ }^{4}$

\begin{abstract}
${ }^{1}$ Department of Mechanical Engineering, Tarbiat Modares University, Tehran, Iran
${ }^{3}$ Department of Polymer Engineering, Tarbiat Modares University, Tehran, Iran

${ }^{4}$ Department of Mechanical Engineering, Coventry University, United Kingdom

* Corresponding author, Ghlia530@modares.ac.ir and G.Liaghat@kingston.ac.uk
\end{abstract} \\ ${ }^{2}$ School of Mechanical \& Aerospace Engineering, Kingston University, London, England
}

\begin{abstract}
This study aims to investigate the impact performance of composite panels consisting of plainwoven Kevlar fabric and rubber matrix. A finite element (FE) model in conjunction with experimental tests was developed to simulate the response of neat fabric and composite under impact loading. Each warp and weft yarn of fabric was individually modeled and combined with rubber matrix network to form the composite. To understand the effect of natural rubber on impact resistance of Kevlar/rubber composites, two types of rubber with different formulation were considered and their mechanical properties were obtained by split Hopkinson pressure bar tests and assigned to the model. Numerical results showed good agreement with the experimental data for both neat fabric and composite. It was shown that rubber matrix improves the ballistic performance of Kevlar fabric by keeping composite flexibility. High hardness rubber matrix composite has higher energy absorption capacity compared to the low hardness rubber matrix composite, due to presence of stronger intermolecular chains. Additionally, deformation and damage mechanism of fabric and composite were investigated under impact loading. The results were presented, discussed and commented upon.
\end{abstract}

Keywords: High velocity impact, Kevlar/rubber composite, Ls-Dyna, Energy absorption. 


\section{Introduction}

Woven fabrics made of high strength fibers such as Kevlar, Twaron and Dynama have attracted considerable attention and are widely used as ballistic protective vest [1]. Ballistic fabrics provide ballistic resistance against high-velocity projectiles. From the point of view of energy transfer, it can be stated that projectile kinetic energy is dissipated through a combination of mechanisms: energy absorption due to stretching and tensile failure of primary yarns, energy absorption due to stretching of secondary yarns, energy dissipated through frictional slips (yarn/yarn and projectile/yarn), and yarn pull-out from the fabric [2-6]. In recent years, extensive studies have been conducted to investigate the impact behavior of fabrics and factors affecting their performance [7-11].

Polymer matrix composites are produced by combining high strength fabrics with a polymer matrix. Matrix plays an important role in ballistic performance of a composite [1214]. Rubber is a good option, which can be used as a matrix in composites. Rubber materials have been widely used in shock absorbers, and other engineering applications $[15,16]$. High flexibility [17] and high damping properties [18] of rubber combined with high strength fabric form an impact resistance composite suitable for blast and ballistic applications. Recently, some studies have been conducted to model the behavior of fabric reinforced rubber composites [19-21]. Ahmad et al. [22, 23] studied the energy absorption of high performance fabrics coated with natural rubber latex and its resistance under impact loading. Higher ballistic limit with the system containing fabric layers coated by natural rubber obtained than the all-neat layer fabric system.

Three important views exist to model a woven fabric in a finite element software: macroscopic [24] (i.e. modeling fabric as an integrated part), mesoscopic [25] (i.e. modeling 
fabric at yarn level) and microscopic [26] (modeling fabric at yarn fibers). In this regard, the mesoscopic method can explain the yarn-to-yarn interactions in the fabric by which the detailed deformation mechanism can be obtained. Accordingly, in recent years, a majority of researchers have used the mesoscale method owing to its low computational costs and accurate answers.

Since there is very little research in the field of impact on composite made of Kevlar fabric and natural rubber matrix, in this work, the behavior of these kind of composite under impact loading was investigated. The mesoscopic view was used and numerical model was validated by experimental data. Two types of rubber with different mechanical properties whose properties were obtained by SHPB tests, were used in simulation, and effect of rubber in energy absorption of composites were studied and compared. Finally, the deformation and failure mechanisms of the fabric and composites under the impact of projectile were analyzed.

\section{Experimental procedure}

\subsection{Materials and sample preparation}

The fabric used in this investigation was a type of plain-woven aramid high performance Kevlar fabric with the areal density of $180 \mathrm{~g} / \mathrm{m}^{2}$ and thickness of $0.23 \mathrm{~mm}$. The samples under consideration were prepared using the two- and four-layer fabric.

Rubber compounding or formulation refers to addition of certain ingredients to raw rubber to obtain the desired properties. In this study two types of rubber with high hardness $(\mathrm{HH})$ and low hardness $(\mathrm{LH})$ were considered, which their formulations are presented in Table 1. Components were mixed and performed on an open two-roll mixing mill (Polymix $200 \mathrm{~L}$, Germany). Dipping method was used to coat Kevlar fabric layers with NR compounds. Coating was carried out by diluting rubber compounds in a toluene solvent. Two and four 
coated fabric layers were assembled and subsequently cured under hydraulic pressure at $160^{\circ} \mathrm{C}$ by a 25 -ton hydraulic press (Davenport, England) based on the rheometer results. The densities of Kevlar/LH rubber composite and Kevlar/HH rubber composite were $1284 \mathrm{~kg} / \mathrm{m}^{3}$ and $1361 \mathrm{~kg} / \mathrm{m}^{3}$, respectively.

\subsection{Flexibility tests}

To measure the flexibility of the targets two-dimensional drape tests were performed according to tests conducted by Lee and Wagner [27]. A $20 \mathrm{~g}$ weight was used, and two-layer Kevlar fabric and $\mathrm{LH}$ and $\mathrm{HH}$ rubber matrix composite targets were tested (Fig. 1). Bending angle is reported as a measure of target flexibility, with larger angles indicating greater flexibility.

\subsection{High velocity impact tests}

High velocity impact tests were performed using a gas gun. The gas gun was made of a pressure vessel of 120 bar capacity, a high speed firing valve, a hollow steel barrel with $6 \mathrm{~m}$ long and a target chamber for fixing samples. The inside diameter of barrel was $10 \mathrm{~mm}$. The initial velocity of projectile was set by gas cylinder pressure. Projectile's velocity, before and after impact, was measured, and ballistic limit was calculated. More detailed description presented in supplementary information.

\subsection{SHPB experiment}

High strain rate tests on the rubber sample were conducted using Split Hopkinson Pressure Bar (SHPB) to obtain its stress-strain properties at different strain rates. The conventional steel SHPB helps to test metal materials, but it cannot precisely determine the dynamic responses of soft materials like rubber [28]. The tests were performed using nylon bars in place 
of metal ones owing to this limitation. The mechanical impedance of nylon bars is much closer to that of the rubber specimens. Thus, the transmitted wave is sufficiently large for measurement (see Supplementary information for SHPB test).

\section{Numerical analysis}

\subsection{Geometrical modeling}

CATIA software (Dassault System, France) was used to establish the complex geometric configuration of the matrix network and the fabric. The fabric used in the present study is plain woven as shown in Fig. 2(a), and the geometry of the yarn was determined by the fabric parameters. The span and thickness of yarns were modeled according to the microscopic images as shown in Fig. 2(b). Yarns were assembled in warp and weft directions to construct a single layer of plain fabric. Owing to symmetry of the projectile-fabric and projectilecomposite systems, only a quarter of the entire two systems was modelled. Fabric and composite systems were modeled with two and four-layer system, and the dimension of model was $50 \times 50 \mathrm{~mm}$. The cross-section of the yarn was assumed as the rectangular shape whose area was equal to actual cross-sectional area of the yarns. Two- and four-layer composites were modeled based on experiments with final thickness of 1 and $2 \mathrm{~mm}$, respectively. It was assumed that the rubber surrounds the fabric layers with equal thickness (Fig. 3). The hemispherical projectile model was cylindrical with a diameter of $10 \mathrm{~mm}$, and the mass of the projectile was $9.32 \mathrm{~g}$, being identical to the projectile used for experimental ballistic tests.

The commercial finite element code of LS-DYNA V971 R4.2 was employed for impact simulation. Symmetry boundary condition was applied in the symmetry planes, and a fixed boundary condition was applied at the edges, as shown in Fig. 4(a). To reduce the number of elements of the multi-layer fabric and ensure the accuracy of the calculation, the hybrid mesh 
was adopted in the model. Fine mesh size was adopted for primary yarns, and coarse mesh size was used for secondary yarns as shown in Figure 4(b). Two- and four-layer neat fabric consisted of 21300 and 42600 elements. Moreover, the number of elements were 159145 and 302536 for two- and four-layer Kevlar/rubber composite, respectively.

\subsection{Mesh convergence}

The mesh convergence was examined on Kevlar/rubber composite before running the simulations on the target. The objective is to find the balance between the running time and the accuracy of the mesh. In this regard, the convergence analysis concentrated on the elements dimension. The residual velocity of the projectile, is the parameter regarded for the assessment, being directly associated with the number of elements. Table 2 reports two different simulations, with four and five elements in the width of primary yarns. Since the two simulations do not significantly differ in the calculation of the residual velocity, the larger element size was used in the simulation to reduce the computational time.

\subsection{Material}

\subsubsection{Kevlar fabric}

The tensile test was performed on fabric yarn to achieve its mechanical properties. The elongation and Young's modulus of the Kevlar yarn were 5\% and $90 \mathrm{GPa}$, respectively. The tensile strength of the yarn was 3.6 GPa. Although the yarns are made of bundled fibers, yarn material is considered to be isotropic. Our result indicated that there is a very slight difference in the energy absorption whether orthotropic material model and the isotropic material model is applied. The volumetric density of the yarn was $1440 \mathrm{~kg} / \mathrm{m}^{3}$, and the Poisson ratio was 0.35 . 


\subsubsection{Rubber matrix}

LS-DYNA offers several material models to simulate rubber-like materials and in this research, Mooney-Rivlin model was chosen which is defined by the following equation:

$$
W=C_{10}\left(I_{1}-3\right)+C_{01}\left(I_{2}-3\right)
$$

Where $C_{10}$ and $C_{01}$ are empirically determined material constants. The Mooney-Rivlin model does not consider the strain rate effect. Nevertheless, the Mooney-Rivlin model can be employed in the simulations with certain adjustment. Figures 5 shows the stress-strain curves at different strain rates obtained by SHPB tests for two LH and HH natural rubbers. Using the impact simulation on pure rubber panel, the strain rate that the material undergoes during the penetration process was estimated. The strain rate of $4000 \mathrm{~s}^{-1}$ was used and fitted with Mooney-Rivlin material model, by applying the least squares approach. Table 3 lists the calibrated coefficients of $C_{10}$ and $C_{01}$. The maximum principal strain was used as the failure criterion of the rubber. The pure rubber panel was modeled by LS-DYNA, and impact response of panel was simulated and verified by our pervious experimental work [29]. Although quasi-static test results indicate that the $\mathrm{HH}$ and $\mathrm{LH}$ rubber elongation to break are approximately $220 \%$ and $350 \%$, from a series of simulations, the failure elongation estimated to be $120 \%$ and $170 \%$ under high strain rate. According to SHPB test, in high strain rates, rubber material behaves stiffer. It was shown that by increasing the strain rate, the strain-stress curve transfers to higher values, which means higher stiffness. On the other hand, it was shown by Roland [30], when an elastomer was loaded in high strain rates, its behavior transfers from elasticity to brittle behavior. This means its elongation capacity decreases and rubber fails at lower strain values. 


\subsection{Contact modeling}

The contact between the projectile and the fabric and rubber matrix was modeled using contact algorithm CONTACT_ERODING_SURFACE_TO_SURFACE. To prevent penetration of fabric layers and warp as well as weft yarns, CONTACT_AUTOMATIC_SURFACE_TO_SURFACE was applied to the model. Based on the results obtained by Rao et al. [31], the static and dynamic coefficients of friction between fabric layers and between the warp and fill yarns were denoted as 0.23 and 0.19 , respectively. There was no de-bonding between the rubber matrix and Kevlar fabric during the high velocity impact; so the CONTACT_TIED_SURFACE_TO_SURFACE algorithm was used to simulate the connection between the fabric yarns and rubber matrix.

\section{Results and discussion}

The main purpose of the current work is to develop and validate a finite element model to evaluate the ballistic performance of Kevlar/rubber composites. The ballistic limit and energy absorption of fabric and composites are investigated in this section, along with a comparison of deformation and stress distribution of specimens under impact loading.

\subsection{Model validation}

To validate the finite element model, the residual velocities of projectile after perforation were compared to the experimental results. Experimental tests offer a wide set of data, being able to cover various impact velocities. At speed values lower than ballistic limit (the minimum velocity required to perforate the target), the projectile fails to perforate the target, and the results were not presented here as it cannot characterize the ballistic performance of specimens; whereas an oblique asymptotic trend of the residual velocity was obtained at higher velocities. Experimental tests were repeated three times at each velocity and average 
presented here. In the numerical simulations, the initial velocity of the projectile was determined according to experimental tests. Figures 6 and 7 present the residual velocities of the projectile relative to initial velocities for two- and four-layer of specimens numerically and experimentally. The slight differences between numerical and experimental analysis could have many causes but are reasonable and the residual velocities from the simulations show good agreement with the test results.

\subsection{Flexibility test results}

The test results for the flexibility are presented in Fig. 8. The flexibility of two-layer Kevlar fabric with bending angle of $55^{\circ}$ and flexibility of Kevlar/rubber composite with bending angle of $51^{\circ}$ and $48^{\circ}$ for $\mathrm{LH}$ and $\mathrm{HH}$ composite is shown. Although Kevlar fabric is more flexible than composites but bending angles show the difference between flexibility of neat fabric and composite is not very much. In fact, using rubber as a matrix causes a little change in the flexibility of Kevlar fabric.

\subsection{Impact resistance evaluation of fabric and Kevlar/rubber composite}

The ballistic limits of two- and four-layer of neat fabric and Kevlar/rubber composites were obtained from numerical simulation. To determine the ballistic limit velocity, simulation was carried out from higher velocity value to lower velocity value, till the projectile perforated the specimen and residual velocity was found to be zero. Result showed that using rubber as a matrix has a significant effect on the fabric's ballistic limit. Figure 9 presents ballistic limit of different samples. It can be seen that the rubber matrix enhances the ballistic limit of neat fabric. The ballistic limits of two- and four-layer Kevlar/LH rubber composite are $15.2 \%$ and $14.4 \%$ greater than two and four-layer neat fabric. These enhancement of ballistic limits are 
$25 \%$ and $31.3 \%$ for two and four-layer Kevlar/HH rubber composite compared to two and four layer of neat fabric, respectively.

It was assumed that the loss of projectile's kinetic energy is equal to the energy absorption performed by the composite target at perforation event. Therefore, the energy absorption of the composite target can be theoretically calculated by subtracting the residual energy of the projectile from its initial energy as presented below.

$$
\Delta E=\frac{1}{2} m\left(V_{i}^{2}-V_{r}^{2}\right)
$$

Where $\Delta E(\mathrm{~J})$ is dissipated energy during the impact process, $m(\mathrm{~kg})$ is mass of the projectile, $V_{i}(\mathrm{~m} / \mathrm{s})$ is projectile initial velocity, and $V_{r}(\mathrm{~m} / \mathrm{s})$ is residual velocity. The energy absorption of LH rubber matrix composites at ballistic limit velocity were $19.4 \mathrm{~J}$ and $42.1 \mathrm{~J}$ for two and four-layer, respectively, indicating $32.9 \%$ and $31.1 \%$ improvement compared to two and four-layer neat fabric. Furthermore, the energy absorption of HH rubber matrix composite were $22.8 \mathrm{~J}$ and $55.4 \mathrm{~J}$ for two and four-layer enhancing the energy absorption of neat fabric approximately $56.2 \%$ and $72.6 \%$. Presence of rubber matrix leads to effective performance of composite. Rubber with high damping properties considerably contributes to energy absorption of the projectile. It is shown that $\mathrm{HH}$ rubber matrix composite has higher energy absorption capacity compared to the LH rubber matrix composite, due to presence of stronger intermolecular chains created by a carbon black filler.

\subsection{Evaluation of fabric and composite deformation}

Yarns in woven fabric, are interlaced together and have relative movement in the fabric. Thus, secondary and primary yarns are stretched and deformed until reaching tensile strength of primary yarns and occurring perforation. The yarn breakage is the most important mechanism 
of energy absorption of fabric shown at the sharpest point of contact between the projectile and the yarns. Figure 10 shows the four-layer neat Kevlar fabric after perforation with the projectile velocity of $150 \mathrm{~m} / \mathrm{s}$. Yarn breakage is shown in both numerical and experimental analysis. Another important phenomenon observed when a hemispherical projectile impacts the woven fabric is wedge through phenomenon. By striking the hemispherical projectile to the neat fabric, it transversely deflects and the fabric mesh is distended therefore, the space between the yarns increases. Consequently, projectile pushes yarns ahead instead of breaking them. Again Figure 10 highlights the agreement of the experimental results in terms of wedge through phenomenon with the numerical ones obtained with the model.

Figure 11 shows the four-layer Kevlar/rubber composite under high velocity impact loading. Based on the experimental and numerical results, the failure modes of low and high hardness rubber matrix composites look like each other and cannot distinguish a specific difference after perforation. Fiber breakage and rubber tearing were the most important failure mechanism occurring when maximum strain reached. This breakage was local, which is shown under the impact point of the projectile. Rubber tearing at behind and front of the composite was observed and occurred after fiber breakage. On the other hand, yarn pull out was not observed for both types of rubber used in this study. Failure mechanism of two and four layer Kevlar/rubber composite was similar without specific difference.

Figure 12(a) shows the impact zone of neat Kevlar fabric after perforation compared to fabric layers inside the composite as shown in Fig. 12(b). Owing to wedge through phenomenon explained in this section, the number of broken yarns in neat fabric was less than the number of yarns intersecting the projectile, while all primary yarns of fabric layers inside 
the composite were broken. Fabric layers inside the composite keep their arrangement due to presence of rubber network and perfect bond between the rubber and fabric yarns.

Transverse displacement waves travel along the primary yarns away from the point of impact when the projectile contacts the fabric. The impact process of a woven fabric encompasses generation of a pyramid-shaped deformation perpendicular to the fabric plane in the impact region. The base of the pyramid spreads and the projectile perforates the fabric through the breaking of primary yarns when the transverse waves reach the clamped edges of the specimen. Figure 13 shows the behavior of the four-layer neat fabric and four-layer HH rubber matrix composite, respectively, against the impact of a projectile with initial velocity of $150 \mathrm{~m} / \mathrm{s}$ at three different times. As can be seen, the layers were separated from each other during the yarn breakage in neat fabric, and the fabric was cluttered after projectile penetration. Unlike neat fabric, integrity and coherence in the composite is shown after perforation due to presence of rubber matrix. Deformation also depends on the initial velocity of the projectile. For high velocities, penetration occurs before deflection reaches the edges of the specimens, and deformation is local.

Figure 14 presents the time required at which projectile breaks the primary yarns and the time at which the projectile perforates the specimen and exits completely. It is indicated that the yarns inside the Kevlar/rubber composite were broken faster than the yarns in the neat fabric. The stress applied by the rubber network to the yarns causes faster yarn breakage. Although there is not a significant difference in yarn breakage between the LH and $\mathrm{HH}$ rubber matrix composites, the yarns in the $\mathrm{HH}$ composite experience the breakage a little sooner than the yarns in the LH rubber composite. This behavior was seen in both two and four-layer specimens. Despite the earlier breakage of the yarn in the composite, the presence of the 
rubber matrix plays an important role in the energy absorption of the composite. Figure 14 indicates that complete perforation time is longer for the composite compared to neat fabric, and the $\mathrm{HH}$ rubber acts more effectively against the projectile impact.

For better understanding of the effect of rubber matrix on fabric performance the Von Mises stress distribution in the neat fabric and the fabric layers inside the composite is shown in Fig. 15. This figure shows that, the stress in the neat fabric can be spread better compared to the composite. At $0.03 \mathrm{~ms}$, the impacted yarns for both the neat fabric yarns and yarns inside the composite experienced high stresses as the bullet pushes the primary yarns in the out-of-plane direction. At $0.06 \mathrm{~ms}$, the stress in the fabric inside the composite in the impact zone reaches the tensile stress, while stress in the neat fabric did not reach the maximum. The interaction between the rubber matrix and fabric yarns escalates the stress in the composite fabric and results in experiencing yield stress earlier. Between 0.06 and $0.09 \mathrm{~ms}$, the stresses in the impacted yarns dropped after the yarns were broken by the penetrating projectile.

Figure 16 displays the projectile velocity histories at the impact velocity of $150 \mathrm{~m} / \mathrm{s}$ on two- and four-layer neat fabric and Kevlar/rubber composites. Projectile perforates the specimens and the residual velocities are different as shown in this figure. Few observations are notable from Figure 16 as follows:

(i) The high hardness rubber composite has the best impact performance which reduce the projectile velocity more than low hardness composite and neat fabric.

(ii) The velocity deceleration rate of the projectile impacting the composite is higher than the neat fabric. Even the deceleration rate of two-layer composite is higher than the four-layer neat fabric. 
(iii) The velocity deceleration rate of composite is directly related to the hardness of rubber. The rubber with higher hardness leads to greater velocity deceleration rate.

(iv) The first level of composite response is affected by the fabric performance causing the intense deceleration of the projectile velocity. After perforation of the fabric, the gradient is gentle due to low module and large elongation to failure of the rubber.

(v) Duration of penetration is longer for the composites with a higher hardness rubber.

\section{Conclusion}

In this paper, the behavior of Kevlar/rubber composite under high velocity impact was investigated. A numerical model in conjunction with experimental tests was developed, which the yarns and rubber matrix were modeled and combined together to form the composite. As an strain rate dependent material, the rubber mechanical properties were obtaind by SHPB tests and assigned to the model. Good agreement between numerical and experimental results was found. The following simulation-based conclusion from the validated model can be drawn from this investigation.

1- The best performance was achieved when using high hardness rubber matrix, increasing the energy absorption of two- and four-layer neat fabric approximately $56 \%$ and $73 \%$, respectively. For the LH rubber matrix composite, 33\% and 31\% increase in the energy absorption were obtained for two- and four-layer fabrics, compared to the neat fabric.

2- Matrix tearing and fiber breakage observed in Kevlar/rubber composite in impact zone while yarn breakage and yarn pullout are the most important damage mechanisms of the neat fabric. The wedge through phenomenon is observed in the neat fabric, while this phenomenon is eliminated in the composite by the presence of the rubber matrix. 
3- Although the yarns inside the Kevlar/rubber composite are broken faster than the yarns in the neat fabric, but the presence of the rubber matrix resultsin longer complete perforation time of composite and higher energy absorption.

\section{ACKNOWLEDGMENTS}

The authors are grateful to the Tarbiat Modares University (TMU) for their financial support.

\section{REFRENCES}

[1] A. Tabiei, G. Nilakantan, Ballistic impact of dry woven fabric composites: a review, Applied Mechanics Reviews 61(1) (2008) 010801.

[2] J.E. Kirkwood, K.M. Kirkwood, Y.S. Lee, R.G. Egres Jr, N.J. Wagner, E.D. Wetzel, Yarn pull-out as a mechanism for dissipating ballistic impact energy in Kevlar ${ }^{\circledR}$ KM-2 fabric: part II: predicting ballistic performance, Textile research journal 74(11) (2004) 939-948.

[3] C. Ha-Minh, A. Imad, F. Boussu, T. Kanit, On analytical modelling to predict of the ballistic impact behaviour of textile multi-layer woven fabric, Composite Structures 99 (2013) 462-476.

[4] A. Khodadadi, G. Liaghat, A. Sabet, H. Hadavinia, A. Aboutorabi, O. Razmkhah, M. Akbari, M. Tahmasebi, Experimental and numerical analysis of penetration into Kevlar fabric impregnated with shear thickening fluid, Journal of Thermoplastic Composite Materials 31(3) (2018) 392-407.

[5] M.H. Pol, G. Liaghat, E. Zamani, A. Ordys, Investigation of the ballistic impact behavior of 2D woven glass/epoxy/nanoclay nanocomposites, Journal of Composite Materials 49(12) (2015) 1449-1460.

[6] T.J. Kang, C. Kim, Energy-absorption mechanisms in Kevlar multiaxial warp-knit fabric composites under impact loading, Composites Science and Technology 60(5) (2000) 773-784.

[7] Y. Wang, X. Chen, R. Young, I. Kinloch, Finite element analysis of effect of inter-yarn friction on ballistic impact response of woven fabrics, Composite structures 135 (2016) 8-16.

[8] S.A. Taghizadeh, G. Liaghat, A. Niknejad, E. Pedram, Experimental study on quasi-static penetration process of cylindrical indenters with different nose shapes into the hybrid composite panels, Journal of Composite Materials 53(1) (2019) 107-123.

[9] T.-L. Chu, C. Ha-Minh, A. Imad, A numerical investigation of the influence of yarn mechanical and physical properties on the ballistic impact behavior of a Kevlar KM2® woven fabric, Composites Part B: Engineering 95 (2016) 144-154.

[10] G. Nilakantan, M. Keefe, E.D. Wetzel, T.A. Bogetti, J.W. Gillespie Jr, Effect of statistical yarn tensile strength on the probabilistic impact response of woven fabrics, Composites Science and Technology 72(2) (2012) 320-329.

[11] H. Ahmadi, G. Liaghat, H. Sabouri, E. Bidkhouri, Investigation on the high velocity impact properties of glass-reinforced fiber metal laminates, Journal of Composite Materials 47(13) (2013) 1605-1615.

[12] H. Wang, P.J. Hazell, K. Shankar, E.V. Morozov, J.P. Escobedo, Impact behaviour of Dyneema ${ }^{\circledR}$ fabricreinforced composites with different resin matrices, Polymer Testing 61 (2017) 17-26. 
[13] A. Khodadadi, G. Liaghat, S. Vahid, A. Sabet, H. Hadavinia, Ballistic performance of Kevlar fabric impregnated with nanosilica/PEG shear thickening fluid, Composites Part B: Engineering 162 (2019) 643652.

[14] B. Vieille, V.M. Casado, C. Bouvet, About the impact behavior of woven-ply carbon fiber-reinforced thermoplastic-and thermosetting-composites: a comparative study, Composite structures 101 (2013) 9-21.

[15] H. Yang, X.-F. Yao, S. Wang, Y.-C. Ke, S.-H. Huang, Y.-H. Liu, Analysis and inversion of contact stress for the finite thickness Neo-Hookean layer, Journal of Applied Mechanics 85(10) (2018) 101008.

[16] E. Tubaldi, S. Mitoulis, H. Ahmadi, Comparison of different models for high damping rubber bearings in seismically isolated bridges, Soil Dynamics and Earthquake Engineering 104 (2018) 329-345.

[17] H. Yang, X. Yao, Z. Zheng, L. Gong, L. Yuan, Y. Yuan, Y. Liu, Highly sensitive and stretchable graphenesilicone rubber composites for strain sensing, Composites Science and Technology 167 (2018) 371-378.

[18] H. Pouriayevali, Y. Guo, V. Shim, A visco-hyperelastic constitutive description of elastomer behaviour at high strain rates, Procedia Engineering 10 (2011) 2274-2279.

[19] Y. Dong, Y. Ke, Z. Zheng, H. Yang, X. Yao, Effect of stress relaxation on sealing performance of the fabric rubber seal, Composites Science and Technology 151 (2017) 291-301.

[20] H. Yang, X.-F. Yao, Y.-C. Ke, Y.-j. Ma, Y.-H. Liu, Constitutive behaviors and mechanical characterizations of fabric reinforced rubber composites, Composite Structures 152 (2016) 117-123.

[21] H. Yang, X.-F. Yao, H. Yan, Y.-n. Yuan, Y.-F. Dong, Y.-H. Liu, Anisotropic hyper-viscoelastic behaviors of fabric reinforced rubber composites, Composite Structures 187 (2018) 116-121.

[22] N. Hassim, M.R. Ahmad, W.Y.W. Ahmad, A. Samsuri, M.H.M. Yahya, Puncture resistance of natural rubber latex unidirectional coated fabrics, Journal of Industrial Textiles 42(2) (2012) 118-131.

[23] M.R. Ahmad, W.Y.W. Ahmad, J. Salleh, A. Samsuri, Effect of fabric stitching on ballistic impact resistance of natural rubber coated fabric systems, Materials \& Design 29(7) (2008) 1353-1358.

[24] C. Lim, V. Shim, Y. Ng, Finite-element modeling of the ballistic impact of fabric armor, International Journal of Impact Engineering 28(1) (2003) 13-31.

[25] S. Chocron, E. Figueroa, N. King, T. Kirchdoerfer, A.E. Nicholls, E. Sagebiel, C. Weiss, C.J. Freitas, Modeling and validation of full fabric targets under ballistic impact, Composites Science and Technology 70(13) (2010) 2012-2022.

[26] M. Grujicic, A. Hariharan, B. Pandurangan, C.-F. Yen, B. Cheeseman, Y. Wang, Y. Miao, J. Zheng, Fiberlevel modeling of dynamic strength of $\operatorname{Kevlar}{ }^{\circledR}$ KM2 ballistic fabric, Journal of Materials Engineering and Performance 21(7) (2012) 1107-1119.

[27] Y.S. Lee, E.D. Wetzel, N.J. Wagner, The ballistic impact characteristics of Kevlar ${ }^{\circledR}$ woven fabrics impregnated with a colloidal shear thickening fluid, Journal of materials science 38(13) (2003) 2825-2833.

[28] L. Yang, V. Shim, C. Lim, A visco-hyperelastic approach to modelling the constitutive behaviour of rubber, International Journal of Impact Engineering 24(6-7) (2000) 545-560.

[29] A. Khodadadi, G. Liaghat, H. Ahmadi, A.R. Bahramian, Y. Anani, O. Razmkhah, S. Asemeni, Numerical and experimental study of impact on hyperelastic rubber panels, Iranian Polymer Journal 28(2) (2019) 113122.

[30] C. Roland, D. Fragiadakis, R. Gamache, Elastomer-steel laminate armor, Composite structures 92(5) (2010) 1059-1064.

[31] M. Rao, Y. Duan, M. Keefe, B. Powers, T. Bogetti, Modeling the effects of yarn material properties and friction on the ballistic impact of a plain-weave fabric, Composite Structures 89(4) (2009) 556-566. 
Table 1 Formulation of compounds

\begin{tabular}{lcc}
\hline \multirow{2}{*}{ Ingredients } & \multicolumn{2}{c}{ Loading (Phr) } \\
& Formulation 1 & Formulation 2 \\
\hline NR & 100 & 100 \\
Carbon Black (N330) & 60 & 40 \\
Zink oxide & 5 & 5 \\
Calcium carbonate & 30 & 30 \\
Spindle oil & 15 & 30 \\
Sulfur & 2 & 1.5 \\
Volcacit & 0.7 & 0.7 \\
\hline
\end{tabular}

Table 2 Four-layer High-hardness composite simulation results with four and five elements in primary yarn width

\begin{tabular}{cccc}
\hline $\begin{array}{c}\text { elements in primary yarn } \\
\text { width }\end{array}$ & $\begin{array}{c}\text { Number of composite } \\
\text { elements }\end{array}$ & $\begin{array}{c}\text { Initial velocity } \\
(\mathrm{m} / \mathrm{s})\end{array}$ & $\begin{array}{c}\text { Residual velocity } \\
(\mathrm{m} / \mathrm{s})\end{array}$ \\
\hline 4 & 302536 & 150 & 97 \\
5 & 314680 & 150 & 96.4 \\
\hline
\end{tabular}

Table 3 Constants of the Mooney-Rivlin material model

\begin{tabular}{lll}
\hline & $C_{10}$ & $C_{01}$ \\
\hline High hardness rubber & 5.6 & 0.5 \\
Low hardness rubber & 2.9 & 0.4 \\
\hline
\end{tabular}

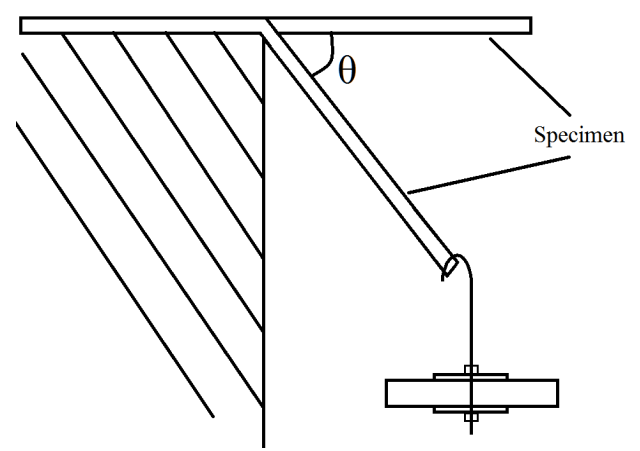

Fig. 1 Test set up for flexibility measurement of sample 


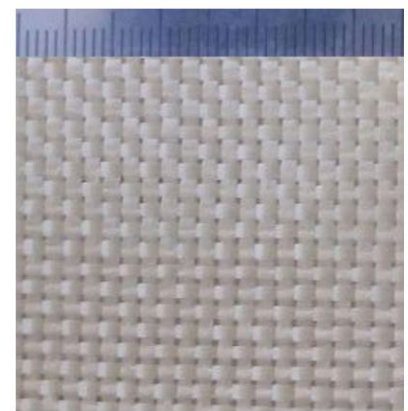

(a)

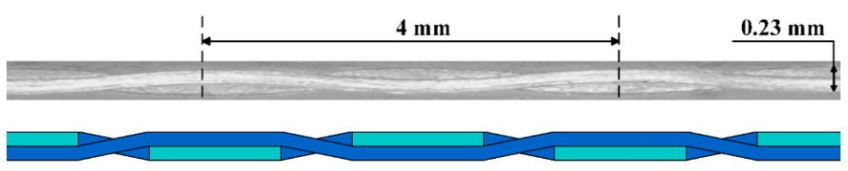

(b)

Fig. 2 (a) plain-woven Kevlar fabric (b) Micrographs and corresponding finite element model of the yarn
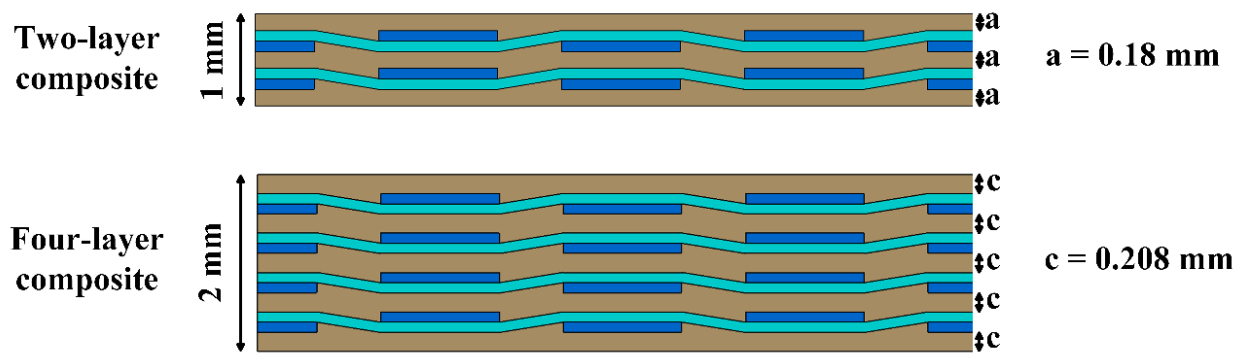

Fig. 3 Two and four-layer Kevlar/rubber composite model
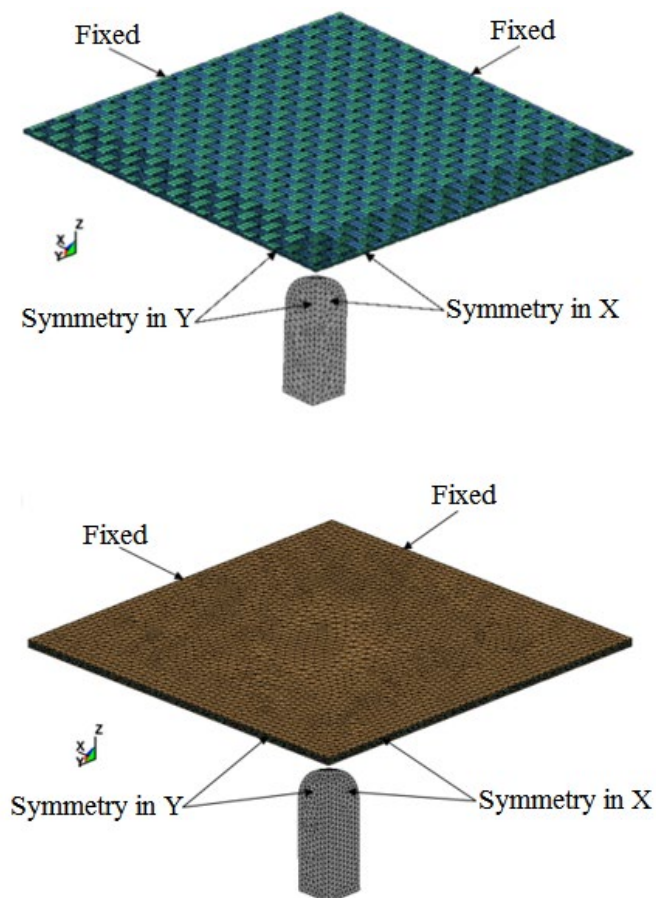

(a)
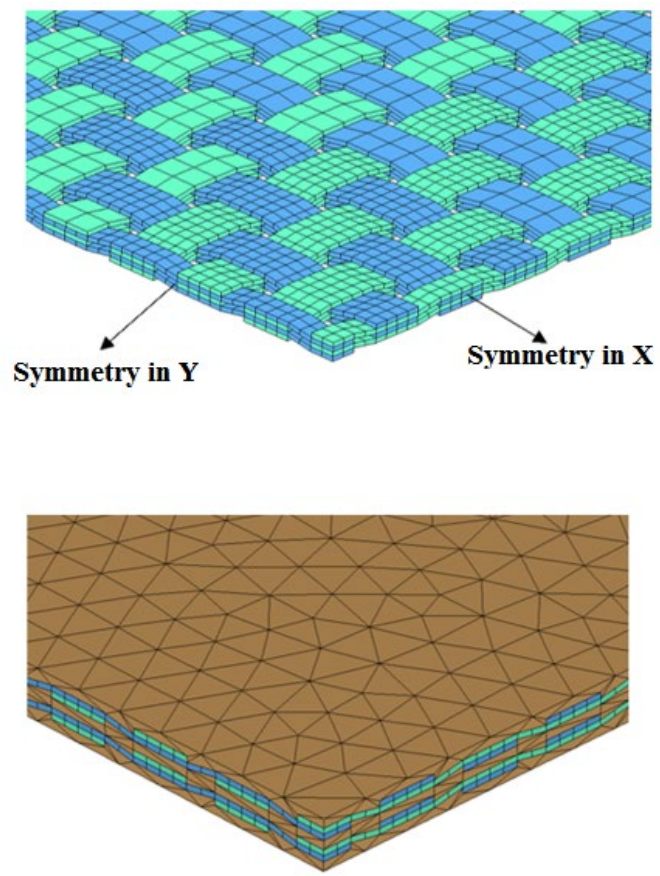

(b)

Fig. 4 (a) Finite element models (b) Fabric and composite mesh 

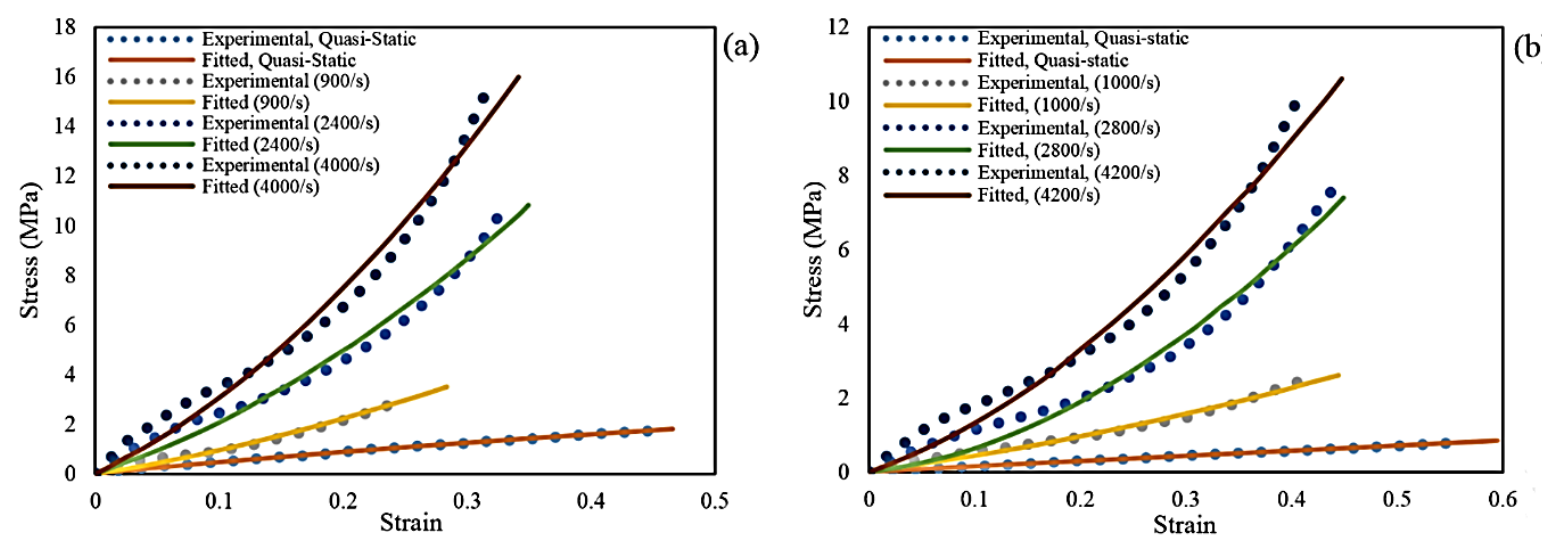

Fig. 5 Stress-Strain curves of rubber at different strain rates (a) high hardness rubber (b) low hardness rubber

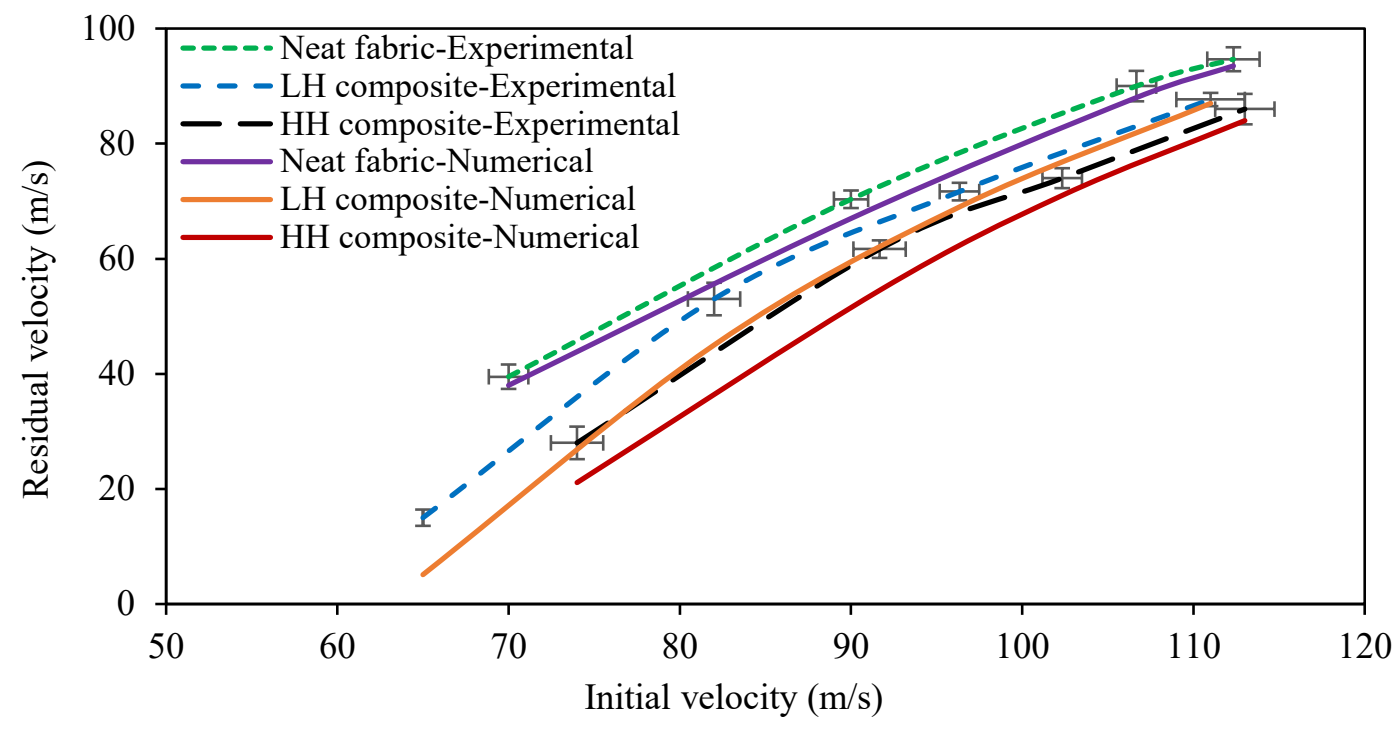

Fig. 6 Experimental and numerical results of impact on two-layer specimens

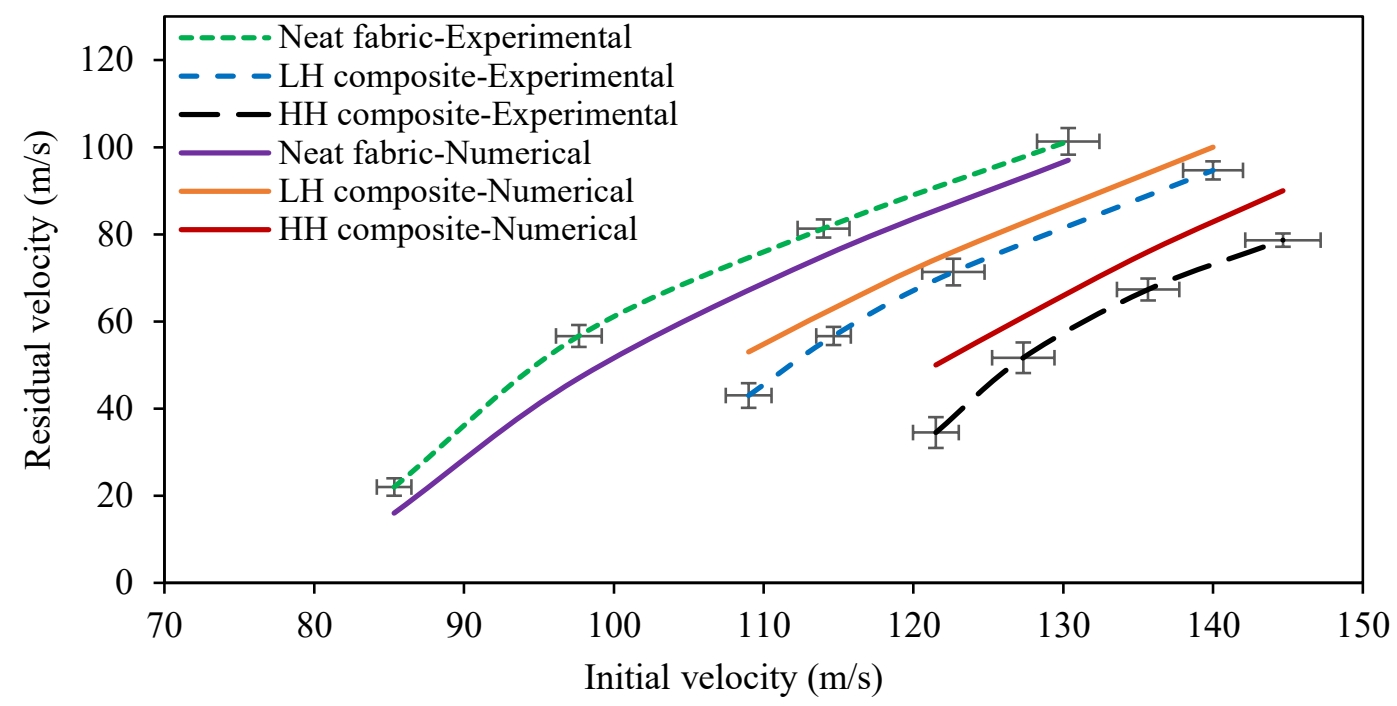

Fig. 7 Experimental and numerical results of impact on four-layer specimens 


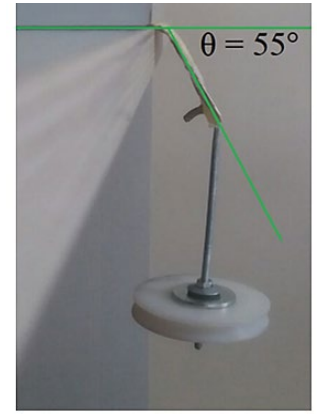

(a)

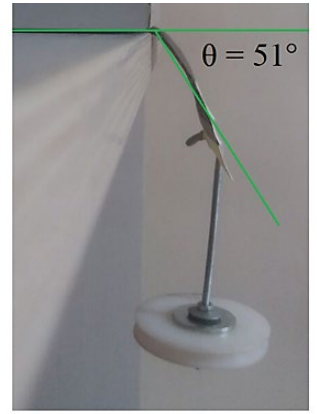

(b)

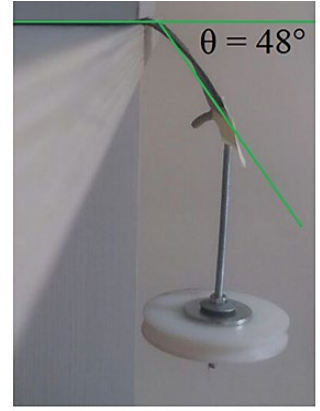

(c)

Fig. 8 Drape test (a) Kevlar fabric (b) Kevlar/LH rubber composite (c) Kevlar/HH rubber composite

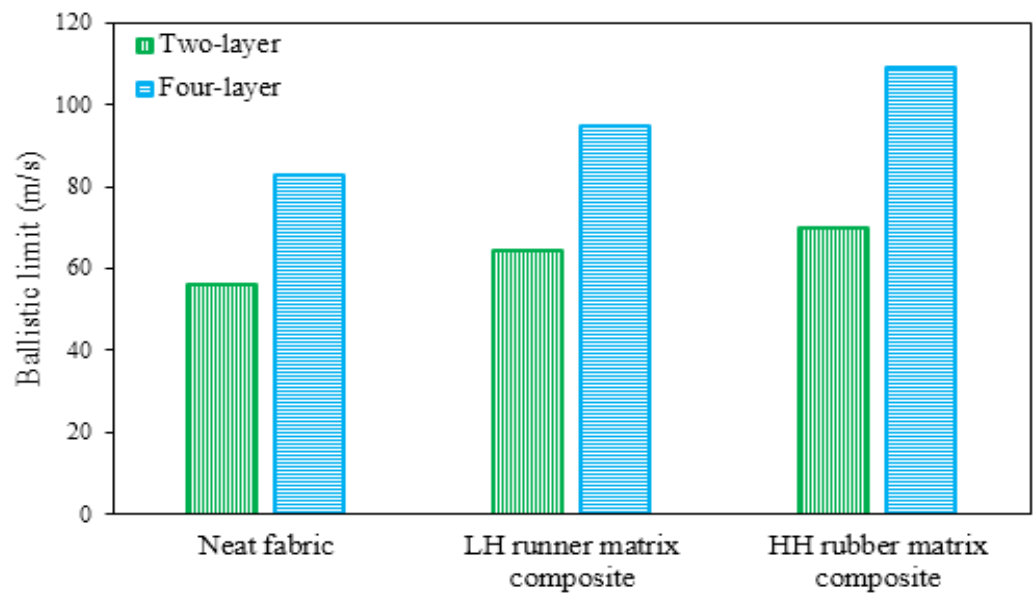

Fig. 9 Ballistic limit of neat fabric and composites
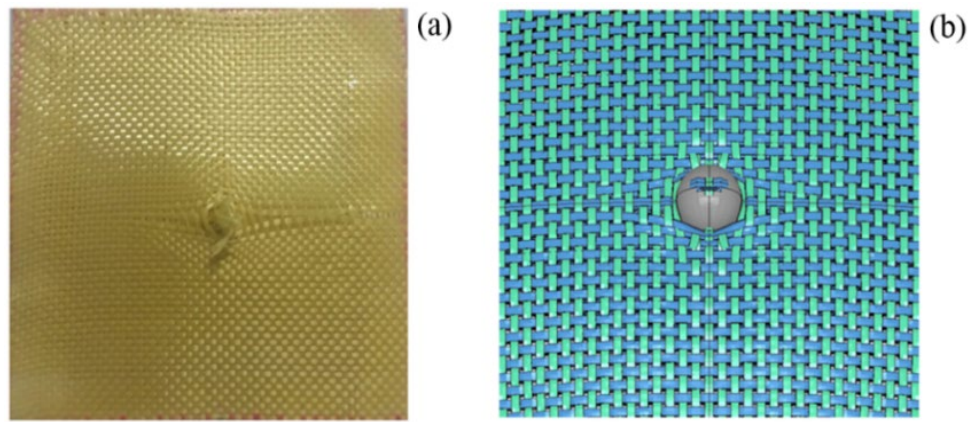

Fig. 10 4-layer neat fabric under impact velocity of $150 \mathrm{~m} / \mathrm{s}$ (a) experiment (b) Numerical simulation
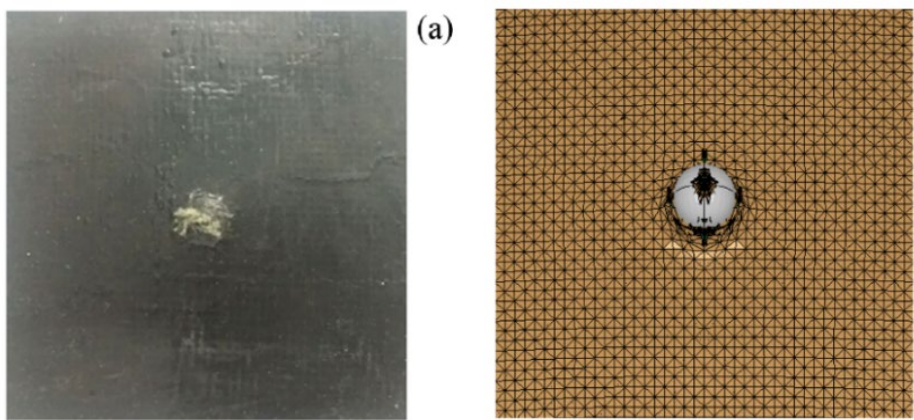

(b)

Fig.11 4-layer Kevlar/rubber composite under impact velocity of $150 \mathrm{~m} / \mathrm{s}$ (a) experiment (b) Numerical simulation 


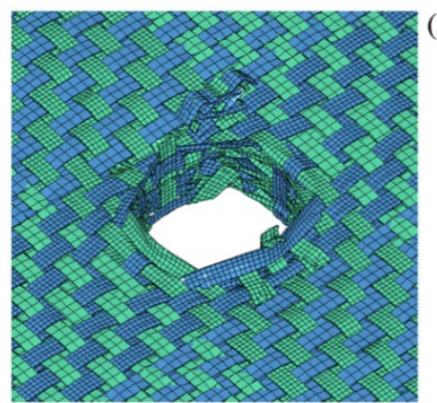

(a)

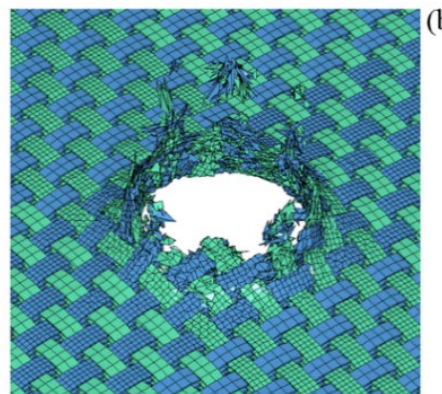

(b)

Fig. 12 Perforation of fabric (a) neat fabric (b) fabric inside composite
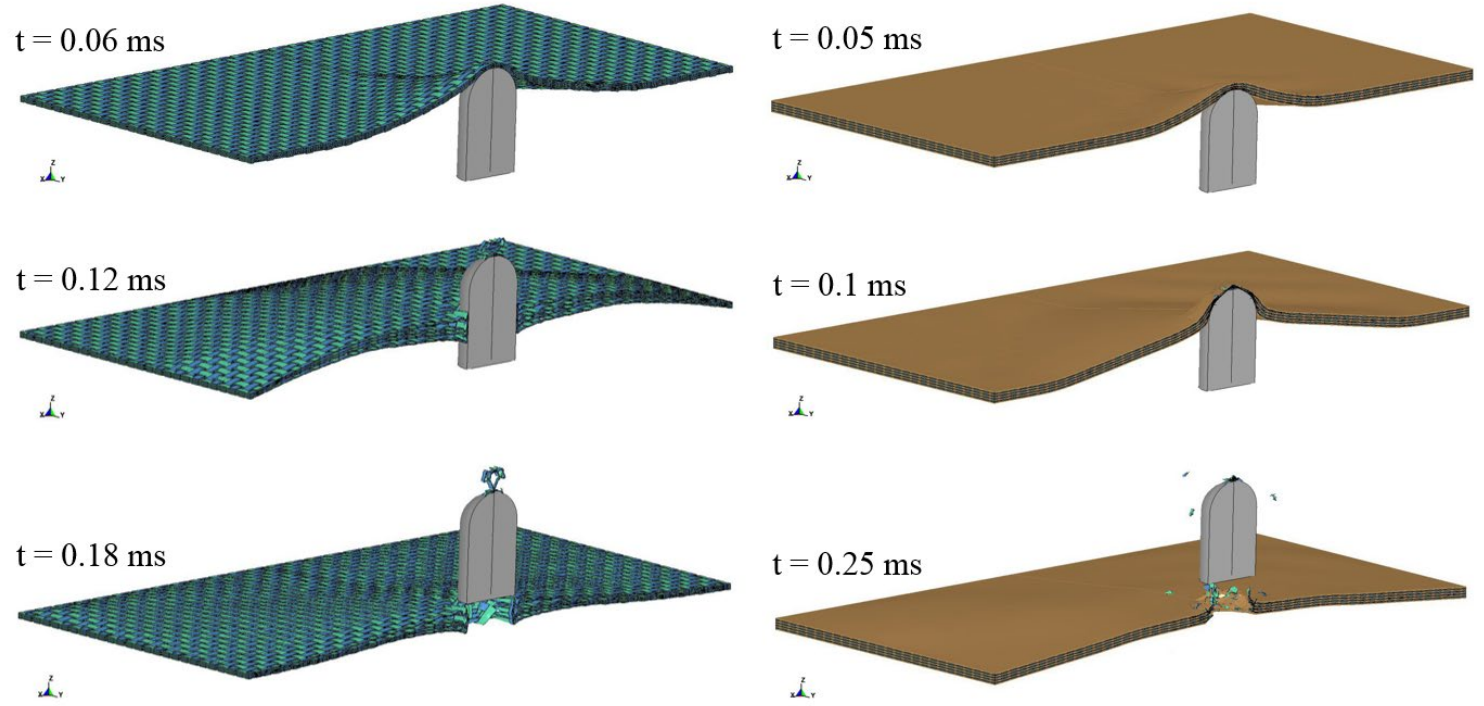

(a)

(b)

Fig. 13 deformation under impact velocity of $150 \mathrm{~m} / \mathrm{s}$ (a) 4-layer neat fabric (b) 4-layer Kevlar/rubber composite

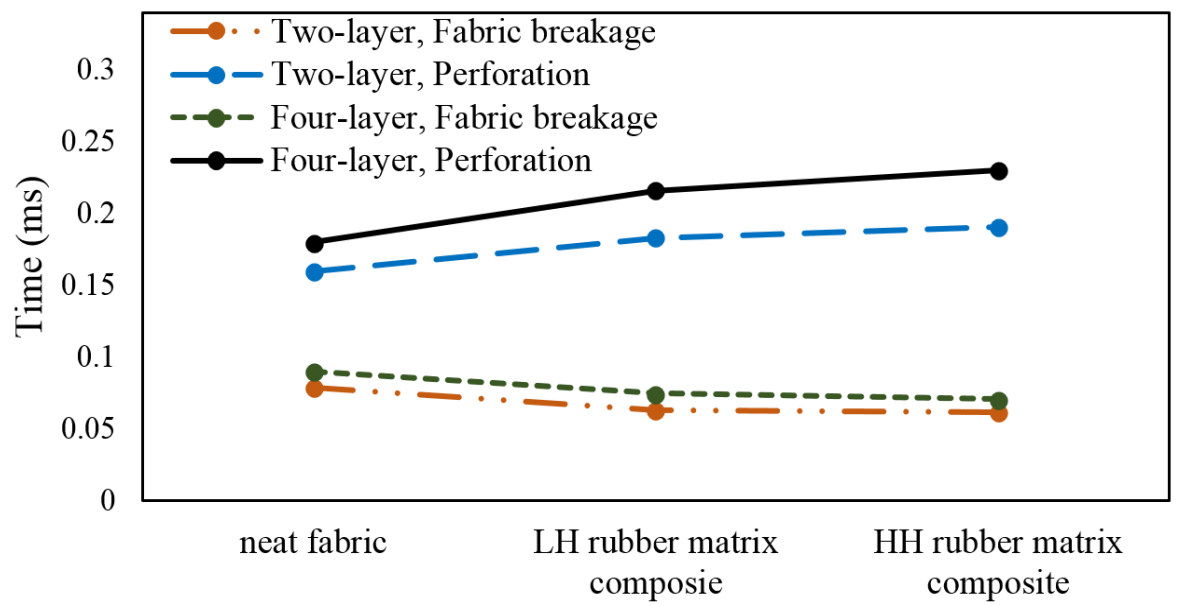

Fig. 14 Time needed for Fabric breakage and complete perforation of two and four-layer neat fabric and LH and $\mathrm{HH}$ rubber matrix composites at impact velocity of $150 \mathrm{~m} / \mathrm{s}$ 

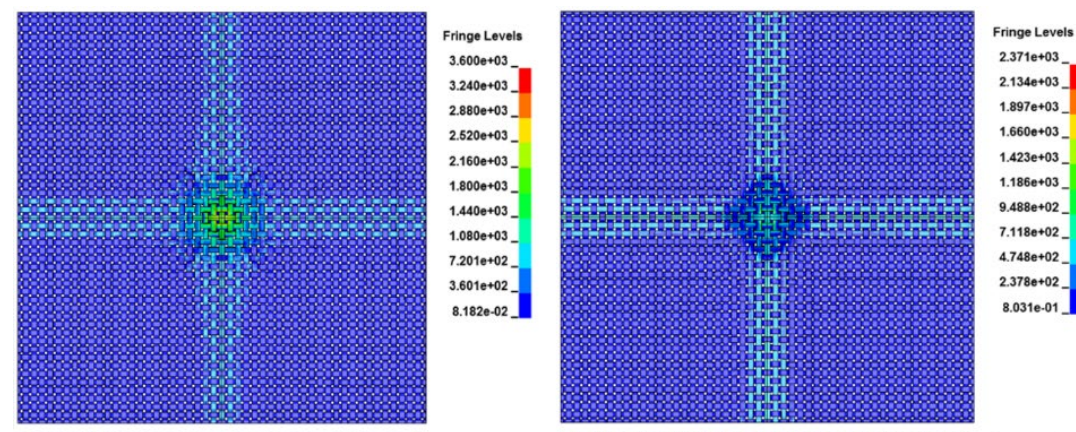

$1.42860+03$

9.488 $\mathrm{e}+02$
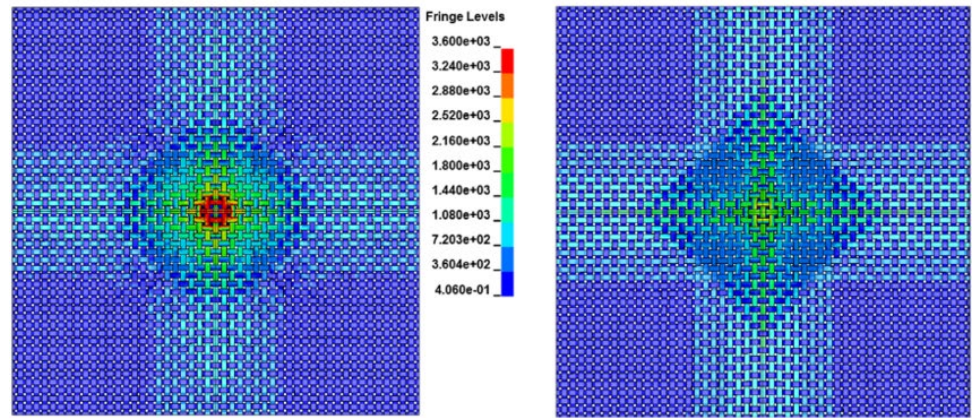

$.748 \mathrm{e}+02$

$2.3780+02$

$\mathrm{t}=0.03 \mathrm{~ms}$

8.031e.01_

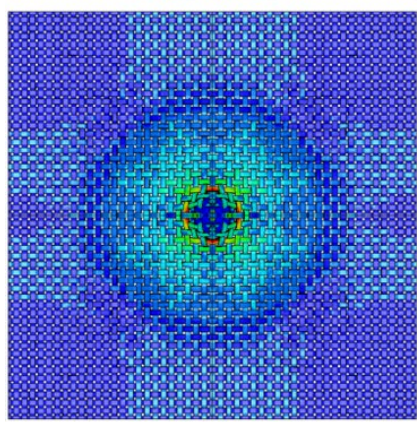

(a)

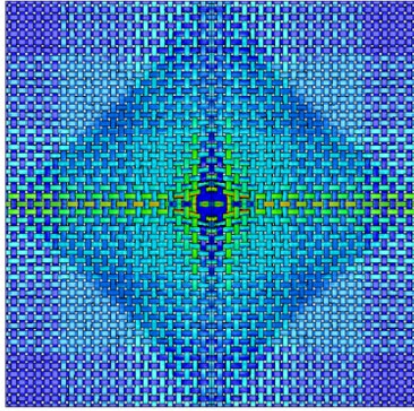

(b)

Fig. 15 Comparisons of different stress distributions during the projectile impact (at $150 \mathrm{~m} / \mathrm{s}$ ) on (a) fabric inside $\mathrm{HH}$ rubber matrix composite and (b) neat fabric

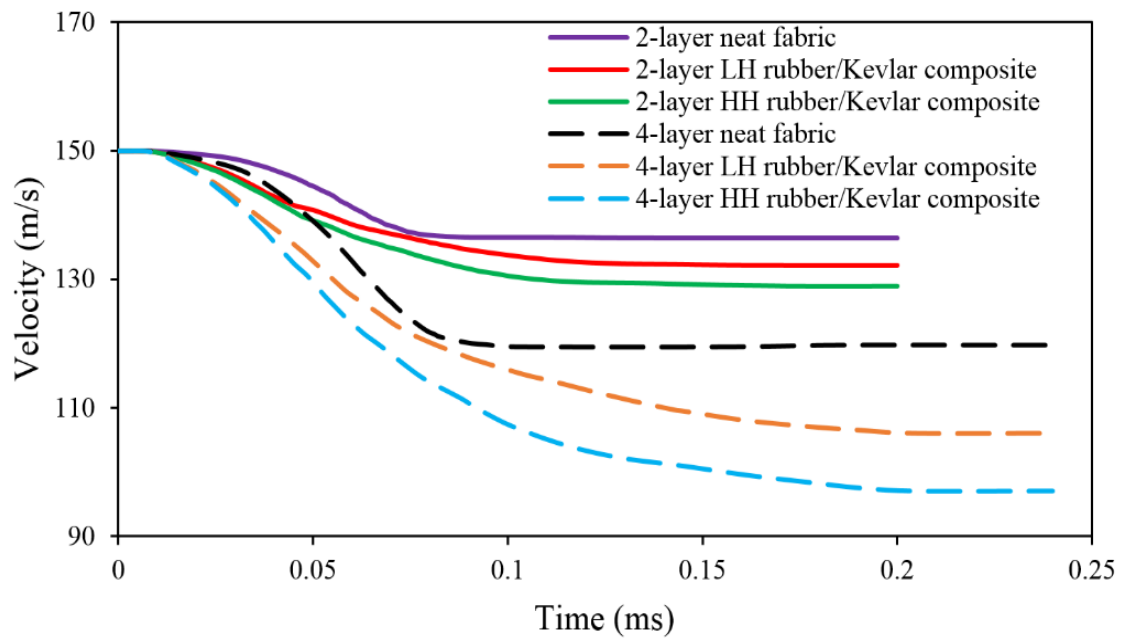

Fig. 16 Comparison of projectile velocity histories at impact velocity of $150 \mathrm{~m} / \mathrm{s}$ on two- and four-layer neat fabric and Kevlar/rubber composites. 